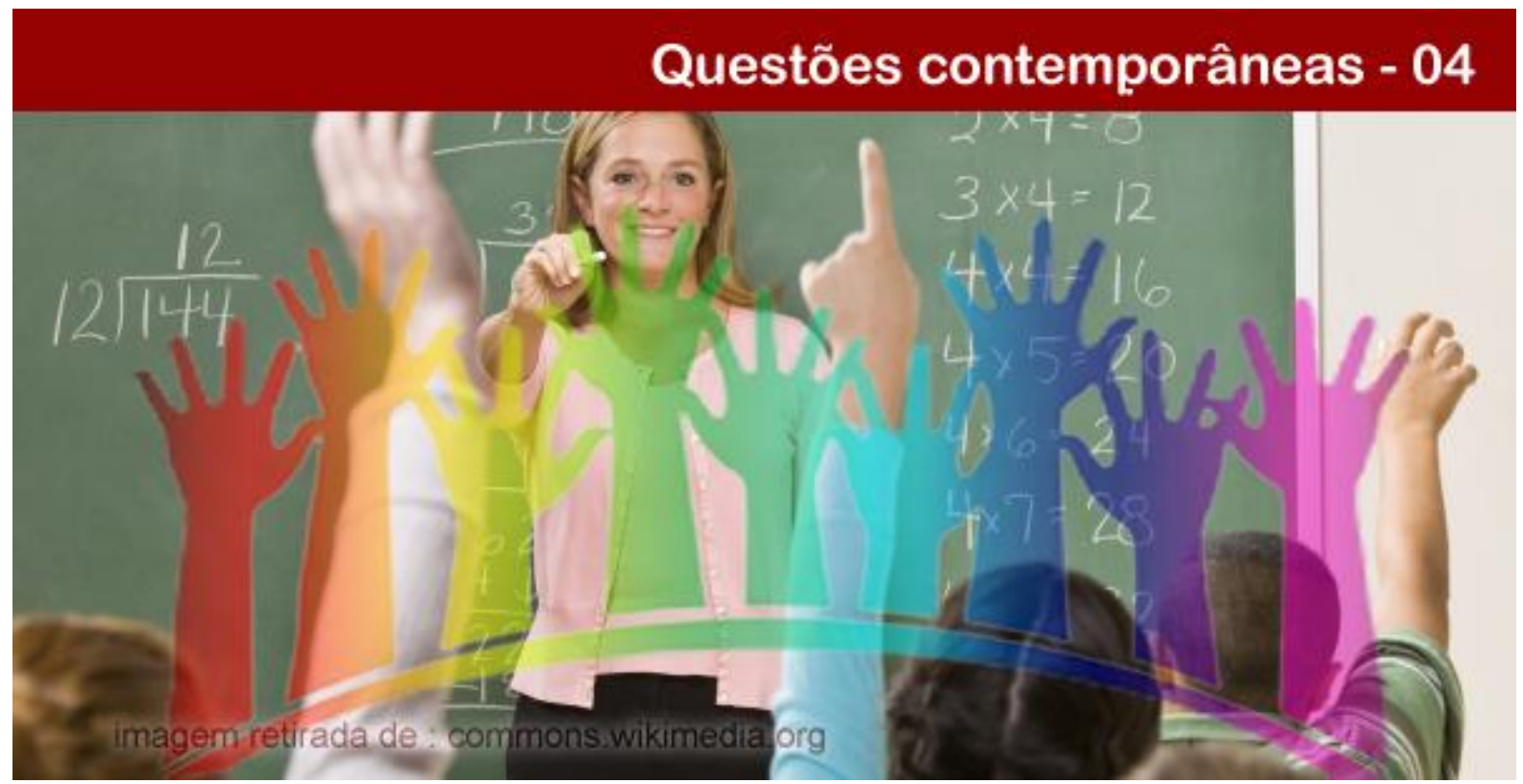

\title{
PROFESSORES EM FORMAÇÃO NO PARFOR: A TEMÁTICA DA HOMOSSEXUALIDADE NA EFETIVAÇÃO DA POLÍTICA LGBTT NA EDUCAÇÃ̃O
}

\section{Claudionor Renato da Silva}

Doutorando em Educação Escolar (UNESP/FCLar). Mestre em Educação (UFSCar). Especialista em Gestão Educacional (UNISEB/COC). Pedagogo (UNIARA/Araraquara/SP). Docente e Pesquisador na Universidade Federal do Tocantins, Câmpus de Arraias (UFT/CUA). Líder do GEPGSEX/UFT/CUA (Grupo de Estudos e Pesquisas Gênero, Sexualidade e Educação). Atua no curso de Pedagogia nas disciplinas de Educação Infantil. E-mail: crenato@uft.edu.br.

\section{Anthéia Augusta Ferreira}

Graduanda do curso de Pedagogia na Universidade Federal do Tocantins, Câmpus de Arraias (UFT/CUA). Integrante do GEPGSEX/UFT/CUA (Grupo de Estudos e Pesquisas Gênero, Sexualidade e Educação). Iniciação Científica na temática da homossexualidade na educação. Bolsista PIBID.

Resumo: Refletimos neste artigo sobre a formação de professores e a temática LGBTT em um curso de Pedagogia, dentro do PARFOR (Plano Nacional de Formação de Professores) na Universidade Federal do Tocantins (UFT), Campus de Arraias (CUA). A temática LGBTT foi apresentada a estes professores sob o aporte da Política LGBTT iniciada pelo Programa Brasil sem Homofobia de 2004. Propor uma reflexão sobre a homofobia escolar não deixa de ser um desafio, pois as instituições, sobretudo religiosas, impedem que os professores em formação se posicionem e interpretem esta realidade na escola de forma cidadã, consciente e científica. A partir de um questionário semiaberto chegam-se a algumas considerações, encaminhamentos, dentre as quais a principal é a necessidade de uma formação e ação junto às unidades escolares na temática da orientação sexual e identidade de gênero, destacando o enfrentamento à homofobia escolar e a necessidade urgente de conhecimentos científicos e pesquisas de Iniciação Científica e Iniciação à Docência sobre o tema, na grande área da Educação Sexual, por entendermos que estes profissionais já estão na sala de aula, nos espaços da escola e em formação universitária.

Palavras-chave: PARFOR. Homossexualidade. Políticas LGBTT.

TEACHER TRAINING IN PARFOR: THE THEME OF HOMOSEXUALITY AND THE LGBTT POLICY EFFECTIVE IN EDUCATION

\section{POLÊM!CA | Revista Eletronica da Ueji}




\begin{abstract}
Reflected in this article on teacher training and the LGBTT theme in course of Education, within the PARFOR (National Plan for Teacher Training) at the Federal University of Tocantins ( UFT ), Campus Arraias ( CUA ). The LGBTT theme was presented to these teachers in the contribution of LGBTT policy initiated by the Program Brazil without Homophobia 2004. A reflection on school homophobia is nonetheless a challenge because the institutions, especially religious, prevent student teachers take a stand and interpret this reality in school citizen conscious and Science. From a semi- open questionnaire to come to some considerations, referrals, among which the main one is the need for training and action with the school units on the subject of sexual orientation and gender identity, highlighting, confronting homophobia school and the urgent need for scientific knowledge and research Scientific Initiation and Introduction to Teaching on the subject in the area of sexual education, because we believe that these professionals are already in the classroom , in the school spaces and training in the university .
\end{abstract}

Keywords: PARFOR. Homosexuality. LGBTT policies.

\title{
Introdução
}

O Plano Nacional de Formação de Professores da Educação Básica (PARFOR), instituído como um Programa nacional por meio do Decreto ${ }^{\circ} 6.755$ de 29 de janeiro de 2009 (Brasil, 2009a), promove, em parceria com a Coordenação de Aperfeiçoamento de Pessoal do Ensino Superior (CAPES), entes federados e Instituições do Ensino Superior, a formação de professores em Licenciatura, prioritariamente, seguido de Segunda Licenciatura e Formação Pedagógica.

Alguns dos princípios do PARFOR (Brasil, 2009a) são muito pertinentes no que diz respeito aos sujeitos LGBTT (Lésbicas, Gays, Bissexuais, Travestis, Transexuais e Transgêneros): com referência à formação de professores, um dos princípios é o direito (Direitos Humanos) e a cidadania “[...] das crianças, jovens e adultos à educação de qualidade, construídas em bases científicas e técnicas sólidas (BRASIL, 2009a, Inciso I, Art. $\left.2^{\mathrm{o}}\right)$ ".

Essa perspectiva, a do direito, é a essência das políticas LGBTT para a educação, para a escola, para a formação de professores, já que as pesquisas e os dados de violência aos sujeitos LGBTT, que englobam também a violência sofrida pelos filhos e filhas destes novos modelos parentais, evidenciam que a escola é um espaço de preconceito e discriminação e que revela, acima de tudo, a necessidade de formação em educação sexual "[...] em bases científicas e técnicas sólidas (BRASIL, 2009a)".

Outro destaque dos princípios é a "emancipação dos indivíduos e grupos sociais (Brasil, 2009a, Inciso II, Art. $2^{\circ}$ ) ”. A Educação Sexual e a diversidade se pautam, atualmente, dentre outras dimensões, na dimensão do caráter emancipatório. Refletir sobre os sujeitos LGBTT na escola implica esta formação docente visando à emancipação sexual dos sujeitos,

\section{POLÊM!CA | Revista Eletronica da ver}


mas também uma postura docente que considere a diversidade sexual, ou seja, a sexualidade do indivíduo que lhe permite olhar o outro com respeito.

Este tema gera muita polêmica, mas é de fundamental importância, sobretudo porque estamos tratando da formação de pessoas, da educação infantil à universidade; pessoas que precisam se humanizar na valorização da diferença, contra a manutenção dos valores que excluem aquele que não é heterossexual e não se "encaixa" no modelo construído. É mais que fundamental este tema polêmico na formação de professores.

No que se refere ao papel da CAPES na parceria com o PARFOR (Brasil, 2009a), há incentivo à pesquisa no espaço escolar visando uma melhor formação dos professores.

\section{Art. 11. A CAPES fomentará ainda;}

I - projetos pedagógicos que visem a promover novos desenhos curriculares ou percursos formativos destinados aos profissionais do magistério;

IV - projetos de revisão da estrutura acadêmica e curricular dos cursos de licenciatura;

$\mathrm{V}$ - pesquisas destinadas ao mapeamento, aprofundamento e consolidação dos estudos sobre perfil, demanda e processos de formação de profissionais do magistério;

VI - programas de apoio a projetos educacionais e de pesquisa propostos por instituições e por profissionais do magistério das escolas públicas que contribuam para sua formação continuada e para a melhoria da escola;

VII - programas que promovam a articulação das ações de formação continuada com espaços de educação não-formal e com outras iniciativas educacionais e culturais (BRASIL, 2009a).

$\mathrm{Na}$ expressão "novos desenhos curriculares ou percursos formativos destinados aos profissionais do magistério" não poderíamos interpretar um convite aos estudos dos sujeitos LGBTT na educação básica, em que os professores já na ativa empenhem-se em pesquisas e projetos que contribuam "para sua formação continuada e para a melhoria da escola", especialmente no enfrentamento de toda forma de preconceito e discriminação aos sujeitos LGBTT no espaço escolar? Pesquisas de Iniciação Científica e de Extensão, propostas pelas Instituições Federais de Ensino, na temática dos sujeitos LGBTT, são um foco de atenção necessário.

Diante da importância destes profissionais que estão em formação universitária e com longo período de prática pedagógica, de experiência no espaço escolar, entendemos que este estudo é de extrema relevância para o contexto do sudeste tocantinense e nordeste goiano, e que tem como objetivo refletir sobre o que pensam os professores em formação e em serviço

\section{POLÊM!CA | Revista Eletronica da Uej}


sobre a homossexualidade masculina e feminina e a necessidade de garantias do bem-estar subjetivo ${ }^{l}$ (Junqueira, 2009a) das e dos sujeitos LGBTT.

\section{Problema e método}

Tendo como base autores como Louro (2004; 2007; 2008), Junqueira (2009a; 2009b), Borrillo (2010) e Alevato (2012), apenas para citar alguns, o problema que norteia este trabalho é: como os professores do curso de pedagogia do PARFOR, da Universidade Federal do Tocantins (UFT), Campus de Arraias, veem a temática da homossexualidade masculina e feminina? Como lidam com essa temática na prática pedagógica e nas relações de trabalho e de amizade com as famílias de seus educandos?

Como pesquisa de cunho qualitativo, optou-se pela organização e aplicação de um questionário semiaberto, segundo Marconi e Lakatos (2003). Etapas:

- Elaborou-se uma série ordenada de perguntas que, uma vez organizadas, foram respondidas sem a presença dos pesquisadores.

- Junto ao questionário, uma nota explicativa da pesquisa.

- Um pré-teste foi elaborado e aplicado com dois participantes e, depois de alguns ajustes, enviados para os participantes de duas turmas de Pedagogia PARFOR.

\section{Homossexualidade, homofobia: desafios à formação de professores e à escola}

A diversidade sexual presente no ambiente escolar provoca uma série de discussões e polêmicas em relação às diferenças e aos direitos dos sujeitos LGBTT.

Sobre a homossexualidade, há registros de sua existência em diversas épocas, diversos povos e com distintos conceitos e considerações. A historicidade apresentada por Borrillo (2010) nos esclarece esse caminhar duplo entre aceitação e resistência; liberdade e proibições. Resistências e privações que se inauguram, sobretudo no ocidente, com a dominação, primeiramente católica e, depois, protestante, mais recentemente nos modelos neopentecostais que, inclusive, elegendo políticos, obstaculizam qualquer avanço político na temática da sexualidade na escola e no Direito.

\footnotetext{
${ }^{1}$ Em linhas gerais, bem-estar subjetivo, conceito discutido por Junqueira (2009a) refere-se à garantia de cidadania e de Direitos dos sujeitos LGBTT de não serem discriminados, desrespeitados nos espaços sociais.
}

\section{POLÊM!CA | Revista Eletronica da Ueij}


Já a homofobia é um termo contemporâneo e designa o medo, a aversão ao homossexual. A pessoa homofóbica não tolera a presença e o convívio com homossexuais, nem o que se refere a eles, por exemplo, modos de relacionarem-se, modos de demonstrar afeto e, principalmente, questões relativas à luta por direitos. Por isso, a homofobia chegou a um alto patamar de violência e discriminação, acarretando até mesmo a morte de homossexuais.

Junqueira (2009a; 2009b) afirma que a homofobia está atrelada a duas situações: uma, o receio de tornar-se homossexual, a outra é que a homofobia se consolida no reforçamento do heterossexismo, geralmente originário do ambiente religioso - heterossexismo, como atesta Junqueira (2009a), é uma atitude mental, mas também manifesta em atitudes que classificam como natural a união de um homem com uma mulher e "enquadram" como nãonatural todos os modelos que fogem à esta regra; classificam as pessoas que fogem deste "comportamento natural" como inferiores, pervertidos, etc.

Partindo destas considerações, a escola tem um papel primordial no combate à homofobia; a conscientização da igualdade, do respeito ao outro e ao diferente. Não podendo compactuar com a disseminação e perpetuação do preconceito e da violência.

Diversos estudos vêm trazendo reflexões com respeito à homossexualidade e à homofobia que necessitam ser inseridos no currículo escolar da educação básica; promover o bem-estar subjetivo (Junqueira, 2009a) dos sujeitos LGBTT significa efetivar no espaço escolar o respeito a estes sujeitos, ou seja, que as políticas LGBTT possibilitem aos professores e gestores sensibilidade em relação aos educandos LGBTT, para que se possa eliminar, de fato, situações de agressão e discriminação contra estes educandos(as) e mais importante: que os profissionais da escola consigam compreender que este educando(a) não é um doente, não precisa ser "incluído"... Precisa ser respeitado(a) como cidadão(ã).

As pesquisas referentes à homofobia destacam as suas diversas facetas e apresentam algumas ações, implementadas na busca da superação do preconceito e da discriminação. Estas pesquisas apresentam um ambiente escolar onde as pessoas que não seguem as normas de gênero são discriminadas, humilhadas, ficando assim, evidente a falta de preparo dos profissionais para solucionar os conflitos e consolidar o bem-estar subjetivo dos sujeitos LGBTT. 
A homofobia assemelha-se a outros tipos de preconceito e discriminação como o de raça, cor, religião, etnia, que tem como finalidade caracterizar o outro como diferente, errado, inferior. São discursos estabelecidos e propagados que se tornam uma verdade absoluta e aceita pela maioria. Os homossexuais há muito tempo sofrem as privações e renúncias, tendo seus direitos negados e criticados pela homofobia relutante. "A homofobia passa a ser vista como fator de restrição de direitos de cidadania, como impeditivo à educação, à saúde, ao trabalho, à segurança, aos direitos humanos [...] (JUNQUEIRA, 2009b, p. 373) ”.

São ações homofóbicas que se amparam na fala de que os homossexuais mancham, sujam e revertem a cultura e os princípios sociais. Com isso, submetem os homossexuais a um tratamento em que os tornam mais inferiores e incapazes de progredir e assumir suas vidas, cuidar de filhos e de uma família.

[...] a diferença sexual entre homem e mulher, assim como a diferença das sexualidades entre heterossexual e homossexual, é apresentada como um indicador objetivo do sistema desigual de atribuição e de acesso aos bens culturais, a saber, direitos, capacidades, prerrogativas, alocações, dinheiro, cultura, prestígio, etc. (BORRILLO, 2010, p. 39).

Todavia, a homofobia, delimitada por essa aversão, agressão ao homossexual, adquire um caráter individual ao situar o sujeito como ponto de partida e não um grupo em si. Pois o homossexual, ao assumir sua condição, está suscetível a sofrer sozinho, sem o amparo até mesmo da família, que muitas vezes, são os primeiros a hostilizá-los. Borrillo (2010) assim diz, que a pessoa homossexual acaba por criar uma guerra interior, diminuindo o seu próprio ser e ego por sua orientação sexual, tendo que enfrentar uma luta consigo mesmo(a) e com a sociedade da qual faz parte, que o(a) priva de ter seus direitos reconhecidos(as), aceitos(as).

A homossexualidade no decorrer de sua história passou por diversas definições, tratamentos e falta de apoios jurídicos e sociais. E tudo isso acarretou um desdobramento violento a que homossexuais são acometidos, passando por situações que, na maioria das vezes, são qualificadas e consideradas como normais, aceitáveis e plausíveis, pelas instituições machistas, como polícia, igreja, família.

Sob esse viés, cabe enfatizar que as normas e os padrões de gênero normatizam e regulam as relações sociais, acentuando os modelos únicos de comportamentos a serem seguidos e reconhecidos. É de se concordar com Junqueira (2009b) quando este diz que: 


\begin{abstract}
A íntima relação entre homofobia e normas de gênero tanto se traduz em noções, crenças, valores, expectativas, quanto em atitudes, edificações de hierarquias opressivas e mecanismos reguladores discriminatórios bastantes amplos. Assim, pode comportar drásticas consequências a qualquer pessoa que ouse descumprir os preceitos socialmente impostos em relação ao que significa ser homem e ser mulher (JUNQUEIRA, 2009b, p. 375).
\end{abstract}

As políticas LGBTT apostam na educação, apostam na escola. Para Silva (2014):

A educação, a escola, o professorado e a gestão educacional em Redes e Unidades de Ensino assumem um local estratégico e fundamental na transformação da sociedade brasileira, ainda muito resistente às uniões homoafetivas e as formas outras de prazer sexual que foge à "norma" aceita: a heterossexual (SILVA, 2014, p. $70)$.

Portanto, ainda há muito que se desenvolver e compreender; há muito a que se lutar, pautando-se em ações que visam o reconhecimento da diversidade e a erradicação do preconceito. No entendimento de que qualquer relação homoafetiva é própria e cabível e que todo ser humano precisa ser respeitado, ter seus direitos garantidos e preservados, independente de sua cor, religião, raça e, principalmente, de sua orientação sexual; afinal, não importa qual é a diferença, importa que ela exista e que precisa ser aceita e respeitada.

A consideração dos documentos oficiais publicados a partir do Programa Brasil Sem Homofobia de $2004^{2}$ como o Plano Nacional de Promoção e Cidadania de Direitos Humanos de Lésbicas, Gays, Bissexuais, Travestis e Transexuais (BRASIL, 2009b) são importantes no delineamento e historicidade das políticas LGBTT no Brasil, sobretudo voltadas à educação escolar. Na área educacional, estas políticas são fundamentais para o reconhecimento e garantia dos direitos às pessoas LGBTT, o que inclui a orientação sexual e a identidade de gênero como temas educacionais e, portanto, curriculares. Pontuando os itens educacionais propostos no documento Brasil (2009b), tem-se:

- $\quad$ combate à discriminação por orientação sexual, identidade de gênero e raça no serviço público;

- $\quad$ combate à homofobia institucional;

- combate à intolerância religiosa em relação à diversidade de orientação sexual e identidade de gênero;

- $\quad$ inserção da temática LGBT no sistema de educação básica e superior, sob abordagem que promova o respeito e o reconhecimento da diversidade da orientação sexual e identidade de gênero;

\footnotetext{
${ }^{2}$ Também referenciado nos textos da área como BSH: Programa Brasil Sem Homofobia.
} 
- garantia a estudantes LGBT, do acesso e da permanência em todos os níveis e modalidades de ensino, sem qualquer discriminação por motivos de orientação sexual e identidade de gênero;

- $\quad$ intersetorialidade e transversalidade (...) combate à homofobia (...) entre as áreas da educação, saúde e seguranças (...);

- $\quad$ produção de conhecimento sobre o tema LGBT;

- utilização de peças educativas e informativas atraentes, criativas e com linguagem adequada aos vários públicos aos quais serão dirigidas;

- $\quad$ inserção do enfrentamento à homofobia e à discriminação de gênero nos programas educativos desenvolvidos pelos órgãos municipais, estaduais e distrital de assistência social;

- $\quad$ desenvolvimento de ações e práticas de Educação em Saúde nos serviços do SUS e de Educação em Saúde nas Escolas com ênfase na orientação sexual e identidade de gênero (BRASIL, 2009b, p. 14 -19).

Alevato (2012) nos indica uma pedagogia para a cidadania dos educandos LGBTT, a pedagogia generativa (ou da indignação? - proposta nossa!):

\begin{abstract}
Vencer a pedagogia da resignação, da submissão, da reprodução e da discriminação, e desenvolver uma pedagogia generativa (...), que valorize a multiplicidade interior, a expressão das possibilidades, sonhos e desejos, é favorecer a fantástica diversidade da criação humana e da autossuperação. Para o (a) educador (a) resta o desafio de pensar a si mesmo (a), ver-se para além da persona, refletir sobre o sentido de seu trabalho e a sociedade na qual gostaria de viver e que ajuda a construir, não apenas nos conteúdos que está determinado (a) a desenvolver em aula, mas também naquilo que transmite e ensina, em todas as oportunidades, especialmente as "invisíveis", as verdadeiras escolas de vida (ALEVATO, 2012, p. 85 , grifos nossos).
\end{abstract}

O compromisso da escola e da educação, nos trânsitos entre a universidade e a unidade escolar, segundo Junqueira (2009a) está voltado à elaboração de diretrizes aos sistemas de ensino contra toda discriminação; focos na:

(...) orientação sexual e identidade de gênero; fomentar e apoiar cursos de formação inicial e continuada de professores sobre sexualidade; formar equipes para avaliar livros didáticos e eliminar aspectos discriminatórios por orientação sexual e identidade de gênero; estimular a produção de materiais educativos sobre orientação sexual e identidade de gênero e superação da homofobia; apoiar e divulgar a produção de materiais específicos para a formação de professores; divulgar informações científicas sobre sexualidade; estimulara a pesquisa e a difusão de conhecimentos que contribuam para o enfrentamento da violência e da discriminação de LGBT; instituir um subcomitê, com participação do movimento LGBT, para acompanhar e avaliar a implementação do BSH $^{3}$ (JUNQUEIRA, 2009a, p. 16).

\footnotetext{
${ }^{3}$ Brasil Sem Homofobia.
}

\title{
POLÊM!CA | Revista Eletronica da Ueij
}




\section{Resultados: sobre a homossexualidade e sobre os sujeitos e políticas LGBTT}

\section{Perfil dos participantes na pesquisa}

Dos 70 participantes da pesquisa, atuam na Educação Infantil 33\%. Nos Anos Iniciais do Ensino Fundamental, 38\%. Atuam nos Anos Finais do Ensino Fundamental, 15\%. O restante atua na EJA ou não responderam.

Sobre o tempo em que atuam na educação, portanto, sem formação superior, já que estão no PARFOR, 6\% estão na sala de aula, num período acima de 20 anos; 44\% estão entre 10 e 19 anos de profissão. Outros 37\% entre 4 e 9 anos de sala de aula. O restante, com menos de 4 anos - uma minoria. Isto demonstra-nos que o público maior dos participantes da pesquisa é, em grande parte, experiente na sala de aula, sabe do cotidiano - conceito de Certeau (1996); problematizado por Le Breton (2013) ao tratar do corpo como matriz da sexualidade.

Certeau afirma:

Cotidiano é aquilo que nos é dado cada dia, nos pressiona dia após dia, nos oprime, pois existe uma opressão do presente [...]. O cotidiano é aquilo que nos prende intimamente, a partir do interior. [...] O que interessa [...] do cotidiano é o invisível (CERTEAU, 1996, p. 32).

Isto significa que o cotidiano está ligado à ideia de lugar, habitabilidade, praticidade, o usável. Certeau defende que o cotidiano é imprevisível, mesmo que tangível e dominado.

No tocante à sexualidade, ao corpo, Le Breton nos adverte com uma proximidade à Certeau que o cotidiano (o fato social) é perpassado pelos corpos. Na teoria da Le Breton defendemos que o alunado LGBTT não é mais um sujeito invisível e excluído, mas um sujeito corporalmente presente na sala de aula e que deve agora ser visto e respeitado pelo professor e pelos colegas. Não pode ser mais, este sujeito, ignorado.

O fato social nunca está congelado, eternizado e, portanto, passível de ser objetivado, a não ser de maneira provisória. Ele está vivo, tecido no interior de uma rede de relações nunca realmente estáveis, sempre em busca de um novo contato. A abundância dos fatos e gestos da vida cotidiana lança, a este respeito, um desafio difícil de sustentar. [...] a sociologia do cotidiano "dá-se a ver em negativo [...] ela é tornada mais precisa por aquilo que ela evita considerar do que por aquilo que ela considera". O infinito do cotidiano (seu infinito também) [...] a banal constatação da fuga do tempo, da acumulação interminável de diferenças ínfimas, mas cuja ação contribui, lenta ou brutalmente, segundo circunstâncias, para transformar a vida cotidiana. [...] A vida cotidiana é o refúgio assegurado, o lugar dos pontos de 
referência seguros, o espaço transicional [...] do adulto (LE BRETON, 2013, p. 141142).

Poderíamos grifar toda a citação acima, mas ela é suficiente para traduzir porque a resistência dos professores em tratar da sexualidade, da homossexualidade, da diversidade sexual é tão cômoda, tão natural, no que diz respeito, sobretudo, ao dado do tempo de serviço e idade dos participantes: o que não se quer ver e constatar é realmente o que incomoda; preferimos olhar o que não nos incomoda. Este cotidiano dos professores atrelado ao seu tempo de sala de aula e idade, bem como religião - dados que serão demonstrados a seguir são elementos fundamentais sobre o cotidiano escolar e os sujeitos LGBTT em suas relações com os professores e os demais colegas heterossexuais, religiosos, etc.

Outro dado do perfil dos participantes que conta, em muito, com o cotidiano e, portanto, com um olhar mais acurado da e sobre a realidade, é a idade. Acima de 41 anos, temos $25 \%$ dos participantes. Entre 34 e 40 anos, 27\%. Entre 26 e 34 anos, $42 \%$ dos participantes. Este indicador é relevante quando se busca encontrar o contexto de vida que subsidiam as concepções destes professores, em como se fundamentam suas percepções sobre a escola e o tema da diversidade sexual.

As mulheres são $86 \%$ dos participantes. Seguindo uma tendência histórica, mas que se nota também como tendência a chegada de homens nessa profissão, sempre considerada feminilizada. No caso do norte do Brasil 8\% de homens está na média nacional apresentada nos estudos coordenados por Bernadete Gatti e Elba de Sá Barreto à UNESCO, em 2009, intitulado Professores no Brasil: impasses e desafios.

Quanto à religião, 62\% afirmam serem católicos e 29\% evangélicos. Apenas 2\% se declararam Espíritas. Nenhuma outra religião foi pronunciada. Todos preferiram se enquadrar em "Outros". Havíamos disposto um leque muito extenso de religiões como muçulmanas, religiões de matrizes africanas, enfim, mas não houve manifestações de identificação religiosa, mas as duas grandes estão na maioria: católicos e protestantes. Religiões que, por natureza, por história e referência, combatem a homossexualidade, instaurando uma homofobia religiosa que se reflete na homofobia escolar, na supervalorização do heterossexismo. Por que a questão religiosa é tão importante nos estudos e políticas contra a homofobia escolar? Se quisermos uma política e uma ação pedagógica anti-homofóbica é preciso o entendimento do laico e da laicidade na política e na educação, garantias da

\section{POLÊM!CA | Revista Eletronica da aej}


Constituição Federal de 1988, mas pouco respeitada no que diz respeito às atitudes e até algumas leis formatadas para reforçar o heterossexismo.

Nos estudos da Educação Sexual, a religião é um dos maiores entraves às discussões relativas à sexualidade e identidade de gênero, sobretudo nos cursos de pedagogia. Figueiró (2010) afirma essa forte influência tanto católica como protestante, na educação e na educação para sexualidade, rigidamente propensa ao controle dos corpos (Le Breton, 2013), como virtude e moral, como um ato de santidade e amor a Deus, o sexo depois do casamento, e o relacionamento entre um homem e uma mulher, como única forma aceita por Deus. As normas católicas não divergem muito das protestantes, tendo como referencial, segundo Figueiró (2010), as Cartas Apostólicas de São Paulo e suas “normas” aos casais.

\begin{abstract}
Não se deve ir, em se tratando de normas, nem aquém, nem além dos prescritos pelas Escrituras, como faziam os fariseus. As práticas sexuais tidas como antinaturais são consideradas pecaminosas, condutas patológicas, enfermidades do ser nessa área, que podem ser saradas pela conversão e santificação (FIGUEIRÓ, 2010, p. 55).
\end{abstract}

É preciso que a universidade contribua para que na formação inicial operacionalize delicadamente, como propõe as Diretrizes Nacionais para os Cursos de Pedagogia e de Licenciatura, uma perspectiva de profissionalidade laica para que os valores éticos, morais religiosos não continuem a dificultar a luta contra a homofobia escolar e, dessa forma, ao invés de contribuir para o seu fim, o perpetua, reforçando o heterossexismo e o corpo como “santo", "puro", guardado para Deus, e assexuado até o casamento heterossexual.

\title{
Como os professores compreendem a homossexualidade?
}

A questão indicou que $86 \%$ compreendem que o termo não se aplica somente aos homens. A maioria dos participantes entendem a diferença da homossexualidade feminina e masculina. Isso é importante, pois uma das prerrogativas do PNCDH-LGBT ${ }^{4}$ no combate à homofobia escolar é, justamente, diferenciar os conceitos de homofobia (preconceito e discriminação a homossexuais masculinos), lesbofobia (preconceito e discriminação a homossexuais femininos), e transfobia (preconceito e discriminação a homossexuais transexuais, travestis e transgêneros).

\footnotetext{
${ }^{4}$ Plano Nacional de Promoção da Cidadania e Direitos Humanos de Lésbicas, Gays, Bissexuais, Travestis e Transexuais (Brasil, 2009b).
} 
O tratamento científico dos termos, também foco da área da Educação Sexual, é imprescindível, já que a invisibilidade na educação homossexual das feminilidades e masculinidades outras, reforça o heterossexismo e, portanto, as práticas homofóbicas, que tem na violência a sua mais alta voz de intolerância e desprezo ao próximo. Sobre isso, Junqueira (2009a) assim explicita:

\begin{abstract}
O processo de invisibilização de homossexuais, bissexuais e transgêneros no espaço escolar precisa ser desestabilizado. Uma invisibilidade que é tanto maior se se fala de uma economia de visibilidade que extrapole os balizamentos das disposições estereotipadas e estereotipantes. Além disso, as temáticas relativas às homossexualidades, bissexualidades e transgeneridades são invisíveis no currículo, no livro didático e até mesmo nas discussões sobre direitos humanos na escola. Essa invisibilidade a que estão submetidas lésbicas, gays, bissexuais, travestis e transexuais comporta a sua exclusão enquanto tais do espaço público e, por isso, configura-se como uma das mais esmagadoras formas de opressão. É inquietante notar que alguém que não pode existir, ser visto, ouvido, conhecido, reconhecido, considerado, respeitado e tampouco amado pode ser odiado (JUNQUEIRA 2009a, p. $30)$.
\end{abstract}

Continuando a questão relativa aos termos científicos necessários para o combate à homofobia escolar e sua identificação/caracterização, 65\% concordam com a diferença das terminologias homossexualidade masculina e feminina; $29 \%$ afirmam que homossexualidade é tanto para homens como para mulheres.

Perguntados sobre a orientação homossexual: $47 \%$ afirmam ser genética, a pessoa nasce homossexual; $43 \%$ afirmam ser opção sexual.

Essa questão divide os participantes. Na tentativa de problematização e provocação, esse dado se aproxima do que foi comentado anteriormente sobre a importância da cientificidade da linguagem e da cientificidade dos conceitos. A reflexão sobre a homossexualidade está para além de ser genético ou não. O fato é que a genitália não determina a sexualidade. As pessoas ao longo da vida orientam sua sexualidade. Discussões no âmbito da genética, se alguém nasce homossexual, parecem querer justificar a homofobia como doença. Por que não se faz uma pesquisa da razão porque as pessoas são heterossexuais? Esta questão da pesquisa está coadunada com os discursos atuais sobre a homossexualidade, tão presente e tão forte nos palcos políticos e midiáticos, marcadamente conflituosos. Alevato (2012) afirma:

Longe, portanto, de pacificado, o assunto traz a controvérsia econômica, religiosa, ética, estética, além de históricos fantasmas sociais que se confrontam e 
confrontarão, em uma dinâmica social instituinte, importante e pouco desprezível para os educadores. Tal controvérsia pode ser percebida na presença de inúmeros comentários de leitores em notícias publicadas na internet envolvendo a homossexualidade (...). A disputa entre posicionamentos favoráveis e contrários, que se enfrentam acirradamente, mostra a centralidade da temática na atualidade e a forte presença de concepções encouraçadas e polarizadas - fora dos quadros normativos oficiais, mas ainda assim disciplinadoras - alimentadas pela fragilidade da racionalidade diante da complexidade dos processos de produção das identidades sexuais (ALEVATO, 2012, p. 75).

As duas citações a seguir, da parte em aberto do questionário aplicado, revelam, como afirma Alevato (2012), que mesmo não estando no âmbito dos documentos oficiais, as divisões de opinião sobre a homossexualidade ser genética ou não, está permeada de valores e concepções, o que emerge a necessidade, como já afirmamos, de uma formação científica em Educação Sexual para tratar especificamente da Orientação Sexual e da Identidade de Gênero.

A homossexualidade eu a vejo como ação de genética. E não por escolha por isso não acho legal a discriminação. Porém, para muitos é um tema ainda difícil de entender e de conviver com a temática (PARTICIPANTE DA PESQUISA).

Eu acho que escolhe o sexo que quiser desde que resista as criticas da sociedade (PARTICIPANTE DA PESQUISA).

A segunda citação afirma que a sociedade é homofóbica. Tal fala, além de perpetuar a homofobia, coloca as pessoas LGBTT sob constante alarde sobre a própria vida, como afirma (Junqueira, 2009a): como garantir o bem-estar subjetivo destes atores sociais?

Em relação ao preconceito, os professores afirmam que há mais preconceito em relação aos homens com relacionamentos homoafetivos do que com mulheres. Mas há um número considerável de respostas (19\%) que consideram o preconceito a mulheres que se relacionam com outras mulheres.

A literatura constata esse dado, além do que, as mulheres, segundo Alevato (2012), são mais recatadas que os homens. No dizer da autora, a homossexualidade masculina, a partir da expressão "sair do armário", conota uma liberdade sexual masculina que até os anos 1990 era escondida, tanto no social, quanto na literatura acadêmica. A homossexualidade feminina ainda é refém de antigos enquadramentos "tradicional-familiares" com pouca ênfase na Orientação Sexual. A orientação sexual é mais fortemente dirigida à homossexualidade masculina. No caso das relações homoafetivas femininas, segundo Alevato (2012), está muito

\section{POLÊM!CA | Revista Eletronica da Ueij}


atrelada às fantasias sexuais masculinas, na excitação por presenciar práticas sexuais entre mulheres.

Quando indagados em que espaços percebem mais o preconceito, as respostas nos indicam como os espaços educativos lidam com a homossexualidade: para os participantes (81\%) indicam que é a sociedade do entorno, os pais, os vizinhos, os arredores da escola. A questão está ligada, portando, ao cenário social de preconceito e discriminação.

Preconceitos que não se limitam ao entorno escolar. No espaço escolar, apenas $17 \%$ afirmam que o preconceito é visível. É um número considerável para se pensar a escola como reprodutora ou não da homofobia materializada nos espaços sociais. Como a pesquisa se limitou ao questionário, com apenas algumas perguntas abertas, não foi possível a apreensão da realidade deste universo dos $17 \%$ que afirmam que o preconceito é visível no espaço escolar. Seriam comentários, por exemplo, "Olha o casal chegando (risos)!” ou "Que horror, isto é demais! Como fica a cabeça desta criança? Quem é o pai?”. Pesquisas etnográficas, observacionais, entre outros métodos que permitam a inserção na realidade escolar, poderão trazer à tona esta evidência de que o espaço escolar é de fato ora reprodutor do preconceito, ora "mascarador", imprimindo o posicionamento do discurso "politicamente correto".

Nesse universo de respostas, é possível compreender a questão seguinte sobre o dia a dia da escola e a forma como a homossexualidade é tratada, vivenciada - considerando os conceitos de cotidiano, já comentados com base em Certeau (1996) e Le Breton (2013). No dia a dia da escola o tema da homossexualidade geralmente é tratado na forma de piadas preconceituosas e discriminatórias $(67 \%)$ e os outros 33\% afirmam que o tema é sempre tratado com desprezo e resistência. Esse dado é fundamental para percebermos que apesar do discurso "politicamente correto", a homofobia está presente na escola e na vivência desses professores que estão na ativa, em serviço e recebendo formação universitária.

O assunto é muito bom, pois a nossa sociedade é muito preconceituosa e se a escola for parceira em discutir e esclarecer sobre essa temática o preconceito com certeza acabaria (PARTICIPANTE DA PESQUISA).

Sobre a prática dos participantes e suas vivências na invisibilidade ou visibilidade de educandos com tendências homoafetivas, $65 \%$ afirmaram que sim, é perceptível a homoafetividade entre os educandos. Isso demonstra-nos como a temática é relevante na formação inicial e continuada de professores, considerando, antes de tudo, que a maioria

\section{POLÊM!CA | Revista Eletronica da Ueij}


destes profissionais, convive e atua, profissionalmente, na Educação Infantil e Anos Iniciais do Ensino Fundamental.

As políticas LGBTT na educação escolar: o que pensam os professores (as)?

Sobre o "Plano Nacional de Promoção e Cidadania de Direitos Humanos de Lésbicas, Gays, Bissexuais, Travestis e Transexuais" (BRASIL, 2009b) as opiniões foram diversas. A pergunta da pesquisa foi: Você concorda com o projeto do BSH, materializado no documento Brasil (2009) que, dentre outras proposições sugere a presença de cotas para professores gays, lésbicas, transexuais e bissexuais nas escolas de educação básica, sobretudo na educação infantil e anos iniciais? ${ }^{5}$

- $\quad 27 \%$ concordam com as cotas;

- $\quad 21 \%$ não concordam;

- $\quad 19 \%$ indicaram que era preciso discutir sobre o tema para ver se não haveria implicações à saúde psicossexual das crianças;

- $19 \%$ afirmam desconhecer o documento e iriam se informar sobre ele;

- $\quad 13 \%$ afirmam não ter necessidade tal empreendimento de cotas para docentes LGBTT.

Essa distribuição das respostas configura a homofobia escolar, bem como a perspectiva heterossexista predominante: $13 \%$ afirmam que não há necessidade desta ação política. Contudo, o cuidado que se toma da análise é que ser contra as cotas não necessariamente significa ser homofóbico(a). Uma profundidade no que se refere aos contextos dos participantes poderia melhor demarcar essa questão.

Confirma-se a matriz heterossexista nas respostas desses professores, mesmo considerando os $27 \%$ que concordam com as cotas, no sentido de que as crianças convivam desde muito cedo com a diversidade sexual e que, para além da heterossexualidade, existe a homossexualidade.

Uma matriz heterossexual delimita os padrões a serem seguidos e, ao mesmo tempo, paradoxalmente, fornece a pauta para as transgressões. É em referência a ela que se

\footnotetext{
${ }^{5}$ Estratégia 1, $\mathrm{n}^{\mathrm{o}}$ 1.1.2. Incluir a população LGBTT em programas de alfabetização, instituir e ampliar programas e projetos na área de saúde e educação nas escolas públicas do país.
} 
fazem não apenas os corpos que se conformam às regras de gênero e sexuais, mas também os corpos que as subvertem (FELIPE; BELLO, 2009, p. 141).

Felipe e Bello (2009), assim como Le Breton (2013), são base para compreensão destes resultados e que traduzem os desafios da educação sexual no norte do Brasil, particularmente o sudeste tocantinense e o nordeste goiano. Se juntarmos as porcentagens que são contra as cotas, aos que desconhecem o documento e aos que querem tomar contato com o mesmo e àqueles permanentemente contra, temos a evidência de um grande investimento em pesquisas para discussão da diversidade sexual nesta formação universitária e em serviço dos participantes da pesquisa.

Problemáticas originadas em torno da temática da homossexualidade e da homofobia na formação de professores PARFOR

As problemáticas aqui levantadas são organizadas no contexto da temática da homossexualidade e da homofobia escolar, na formação de professores do Programa PARFOR. São oriundas da literatura sobre o tema e o questionário semiaberto aplicado aos docentes, que, como já apontado, tem suas limitações, mas que não deixa de ser um universo contextualizado para as reflexões mais amplas que se seguem e que devem ser aprofundadas em outras pesquisas na temática. Diante disto, as problemáticas empreendidas são as seguintes:

- Uma problemática inicial que evidencia a homofobia escolar na educação básica e que, portanto, não pode ser mais silenciada, rejeitada.

- Um problema de conceituação e de fundamentação em Educação Sexual no currículo de formação de professores deste Programa (PARFOR); conceituações, metodologias (práticas pedagógicas) e práticas políticas em: sexualidade, homofobia, homossexualidade masculina e homossexualidade feminina.

- Uma forte presença de posicionamentos advindos de senso comum, de religiosidade e de um preconceito velado nas respostas encontradas, o que implica, a partir da problemática anterior levantada, uma perspectiva de formação política e social docentes (práticas políticas no espaço escolar visando a diversidade).

\section{POLÊM!CA | Revista Eletronica da Uej}


- Uma minoria dos participantes manifestando a disposição de conhecer um pouco mais dos estudos sobre a homofobia escolar e o seu enfrentamento na busca de uma sociedade que respeita os Direitos de cada cidadão por sua orientação sexual. A problemática aqui se dirige, portanto, a uma demanda que se apresenta possível e positiva na formação destes professores, dentro do PARFOR.

\section{Encaminhamentos da política LGBTT na educação... finalizando}

Então, quais desafios se configuram para a formação de professores em cursos de pedagogia, particularmente as formações em serviço do PARFOR? Podem ser indicados, a princípio, cursos, oficinas. Uma disciplina Optativa? Seriam propostas muito simplistas, pois se entende que formações, muitas vezes, sem acompanhamento avaliativo de implementação, visando à transformação social, são inoperantes. Ganham-se certificados, aumentos salariais ou pontos no Plano de Carreira que não levam ao ponto central que é preciso atacar: o bemestar dos sujeitos LGBTT e novo(s) olhar(es) dos gestores, coordenadores e docentes.

O caminho que se sugere é este que está no próprio modelo de formação do PARFOR: pesquisas em formação. Há um erro nestas formações em desconsiderar o estágio e utilizar aquela frase: "a prática eu tenho, quero a teoria". Neste caso, toda prática que se fizer durante o curso, o aprendiz em formação deve deixar a posição de mestre e se tornar estudante. Selma Pimenta (Pimenta, 2012) afirma e reafirma isto: o professor em formação, se não engendrar em prática de ensino e pesquisa, ele nunca compreenderá e vivenciará a práxis pedagógica ou a práxis dialética. Docentes que afirmam que no PARFOR só buscam a teoria, porque já tem a prática, não compreenderam a práxis. Portanto, é na pesquisa em formação, sendo estudante, que o professor PARFOR vai incrementar sua prática, fomentar sua formação continuada e possibilitar, assim, as transformações do espaço escolar em que as transformações pessoais e das práticas das aulas desse professor(a) são uma consequência natural. Tudo está conectado, interligado. Se não houver este olhar para o produto consequente de uma ação, a formação será só um título para aumento salarial e construção da carreira.

Que ações transformadoras, pela práxis, serão produzidas, se este movimento formação continuada/pesquisa/melhorias da escola for iniciado?

\section{POLÊM!CA | Revista Eletronica da Ueri}


- Será possível ser visualizada a emancipação (sexual) do docente (formação em educação sexual: conceitos e métodos), para que este inicie a emancipação do indivíduo-educando e da coletividade com que convive, dia a dia: sujeitos heterossexuais e sujeitos LGBTT.

- Em decorrência do movimento anterior, emergirá um novo olhar, aquele que Le Breton (2013) afirma que, em relação aos sujeitos LGBTT se nega, não se quer ver. Neste novo outro olhar, os sujeitos LGBTT terão garantidos (as) seu bemestar subjetivo, sua emancipação sexual, o desfrute de seu direito, sobre seu corpo, sobre sua sexualidade. Os sujeitos LGBTT passarão a ser ouvidos e aceitos presencialmente nas salas de aula.

- Destaca-se como fundamental a laicidade do Estado e a laicidade da escola. Geralmente, é comum na região norte do Brasil, a reza para começar a aula, a reza no almoço, a reza, a reza... A oração... A música da Igreja, enfim. Professores reproduzem no espaço escolar as práticas religiosas pessoais do final de semana, sejam eles católicos (as) ou protestantes. Este ponto é fundamental para os processos de uma aceitação dos novos modelos familiares e as novas formas de comportamento sexual em nossa sociedade contemporânea. De fato, pesquisas vêm comprovando os efeitos da extrema religiosidade com marcas profundamente homofóbicas: a homofobia religiosa se reproduz e se transforma em homofobia escolar, homofobia docente.

Ao finalizar as considerações aqui refletidas, defende-se que a política LGBTT para a área educacional seja efetiva e coadunada com a formação de professores do PARFOR, em cursos de Pedagogia, mas também para todas as demais licenciaturas. Aplicável também nos cursos chamados tradicionais ou regulares.

Que a escola seja este lugar de paz, de Direitos, de aceitação e respeito à sexualidade dos sujeitos em nome de uma coletividade. Um espaço do aprender que empodere o coletivo a ponto de eliminar o preconceito e a discriminação para com aqueles que não se enquadram no "padrão". Que um dia não sejam mais necessárias leis para educar os homens sobre o respeito à diversidade, em seu sentido mais amplo possível, mas os homens se educarão pela consciência, pela responsabilidade, pela cidadania e pelo respeito ao próximo numa ação política, dia a dia.

\section{POLÊM!CA | Revista Eletronica da Uej}




\section{Referências}

ALEVATO, H. Nexus \& Sexus: transformações docentes. In: REIS, M. A. S.; ALEVATO, H. (Org.). Nexus \& Sexus: perspectivas instituintes. Rio de Janeiro: FAPERJ, 2012. p. 55- 88.

ALMEIDA, A. N. A construção de masculinidades na fala-em-interação em cenários escolares. Tese de doutorado. Programa de Pós-graduação em Letras, Universidade Federal do Rio Grande do Sul, Porto Alegre, RS, 2009.

BORRILLO, Daniel. Homofobia: história e crítica de um preconceito. Belo Horizonte: Autêntica Editora, 2010.

BRASIL. Decreto n ${ }^{\circ}$ 6.755, de 29 de janeiro de 2009. Institui a Política Nacional de Formação de Profissionais do Magistério da Educação Básica, disciplina a atuação da Coordenação de Aperfeiçoamento de Pessoal de Nível Superior - CAPES no fomento a programas de formação inicial e continuada, e dá outras providências. 2009a. Disponível em: <http://www.planalto.gov.br/ccivil_03/_ato20072010/2009/decreto/d6755.htm>. Acesso em: $1^{\mathrm{o}}$ jun. 2015.

BRASIL. SECRETARIA ESPECIAL DOS DIREITOS HUMANOS. Plano Nacional de Promoção e Cidadania de Direitos Humanos de Lésbicas, Gays, Bissexuais, Travestis e Transexuais. Brasília, DF: SEDH, 2009b.

CERTEAU, M. A invenção do cotidiano 2: morar, cozinhar. Petrópolis: Vozes, 1996.

FELIPE, J.; BELLO, A. T. Construção de comportamentos homofóbicos no cotidiano da educação infantil. In: JUNQUEIRA, R. D. (Org.). Diversidade sexual na escola: problematizações sobre a homofobia nas escolas. Brasília: Ministério da Educação, Secretaria de Educação Continuada, Alfabetização e Diversidade, UNESCO, 2009. p. 141-157.

FIGUEIRÓ, M. N. D. Educação sexual. Retomando uma proposta, um desafio. Londrina: EDUEL, 2010.

JUNQUEIRA, R. D. Introdução. Homofobia nas escolas: um problema de todos. In: JUNQUEIRA, R. D. (Org.). Diversidade sexual na escola: problematizações sobre a homofobia nas escolas. Brasília: Ministério da Educação, Secretaria de Educação Continuada, Alfabetização e Diversidade, UNESCO, 2009a. p.13-51.

JUNQUEIRA, R. D. (Org.). Educação e homofobia: o reconhecimento da diversidade sexual para além do multiculturalismo liberal. In: JUNQUEIRA, R. D. (Org.). Diversidade sexual na escola: problematizações sobre a homofobia nas escolas. Brasília: Ministério da Educação, Secretaria de Educação Continuada, Alfabetização e Diversidade, UNESCO, 2009b. p. 367-444.

LE BRETON, D. Antropologia do corpo e modernidade. $3^{\text {a }}$ ed. Petrópolis: Vozes, 2013.

LOURO, G. L. Gênero, sexualidade e educação: uma perspectiva pós-estruturalista. 10a ed. Petrópolis: Vozes, 2008.

LOURO, G. L. (Org.). O corpo educado: pedagogia da sexualidade. Belo Horizonte: Autêntica, 2007.

LOURO, G. L. Um corpo estranho: ensaios sobre sexualidade e teoria queer. Belo Horizonte: Autêntica, 2004.

MARCONI, M. A.; LAKATOS, E. M. Fundamentos de metodologia científica. $5^{\text {a }}$ ed. São Paulo: Atlas, 2003.

PIMENTA, S. G. O estágio na formação de professores. Unidade teoria e prática? 11ª ed. São Paulo: Cortez, 2012.

\section{POLÊM!CA | Revista Eetrônica da veri}


SILVA, C. R. Homofobia escolar: um assunto para a formação de professores em cursos de pedagogia a partir do PNCDH-LGBT. In: RISCAROLI, E. Diversidades diálogos (im)pertinentes entre educação, literatura e sexualidade. $1^{\text {a }}$ ed. Curitiba: CRV, 2014.

Recebido em: 02/06/2015.

Aceito em: 02/10/2015. 